\title{
Revisiting the lacquer peels method with pyroclastic deposits: sediment plates, a precise, fine scale imaging method and powerful outreach tool
}

Guilhem Amin Douillet ${ }^{1,2 *}$, Ulrich Kueppers ${ }^{1}$, Célia Mato ${ }^{3}$, Quentin Chaffaut ${ }^{1,4}$, Mélanie Bouysson ${ }^{4}$, Renate Reschetizka ${ }^{1}$, Inga Hoelscher ${ }^{1}$, Patrick Witting ${ }^{1}$, Kai-Uwe Hess ${ }^{1}$, Alexander Cerwenka ${ }^{5}$,

Donald B Dingwell ${ }^{1}$ and Benjamin Bernard ${ }^{6}$

\begin{abstract}
Pyroclastic sedimentary successions record an eruptive history modulated by transport and depositional phases. Here, a field technique of outcrop impregnation was used to document pyroclastic sediments at the scale of individual laminae. The details so obtained have the potential to reveal new insights into the dynamics of transport and deposition of pyroclastic currents and fallout.

Sediment plates (a type of lacquer peels) represent a sampling method whereby a thin plate of undisturbed sediments is obtained directly from the outcrop. A low-viscosity, hardening epoxy resin is applied to a freshly exposed cross-section of an unconsolidated deposit and impregnates a surface layer of the cross-section via capillary forces before solidifying. Upon hardening, a solid plate $(0.5-5 \mathrm{~cm}$ thick and up to $2 \mathrm{~m}$ in length) of the sedimentary formation can be recovered and transported with full preservation of the initial organization of the particles. Sediment plates are capable of recording and highlighting details of stratification to a very fine scale and high degree of precision. This method represents a valuable tool for research, education, and exhibition purposes.

A dataset of $50 \mathrm{~m}^{2}$ of sediment plates was created from the primary sedimentary structures emplaced during 1) the August 2006 eruption of Tungurahua volcano (Ecuador), 2) the Laacher See eruption (Germany) and 3) Astroni surge deposits (Campi Flegrei, Italy). This dataset has been put to use in several contexts: 1) analysis of sedimentation processes at the boundary-layer scale, 2) data comparison with remote measurements (e.g., ground penetrating radar), 3) archiving and conservation, 4) as teaching material and 5) for dissemination exercises during exhibition in museums.
\end{abstract}

Keywords: Lacquer peels, Sediment plates, Tungurahua, Laacher see, Astroni, Pyroclastic currents, Bedforms, Sedimentology

\section{Introduction}

\section{Sediment plates}

Sediment plates (a type of lacquer peels) are meterscale, planiform samples of unconsolidated deposits that have been preserved in their original state (including particle locations and orientations, textures

\footnotetext{
* Correspondence: guilhem.douillet@geo.unibe.ch

${ }^{1}$ Earth and Environmental Sciences, Ludwig-Maximilians-Universität München, München, Germany

${ }^{2}$ Institut für Geologie, Universität Bern, Bern, Switzerland

Full list of author information is available at the end of the article
}

and sedimentary structures) via hardening of an impregnated epoxy in situ in the field (Fig. 1a). Here, we refer to "sediment plates", since the term "lacquer peels" implies the idea of sampling by the "peeling off", with its concomitant flexuring of an extremely thin skin of sediment (often glued on a cloth), whereas the dataset presented here is composed of rigid "boards" of hardened cross-sections of sediment strata. These sediment plates have a thickness of several particle diameters (typically 3-50 mm-thick) and possess areas of $\mathrm{dm}^{2}$ to $\mathrm{m}^{2}$. The technique for 

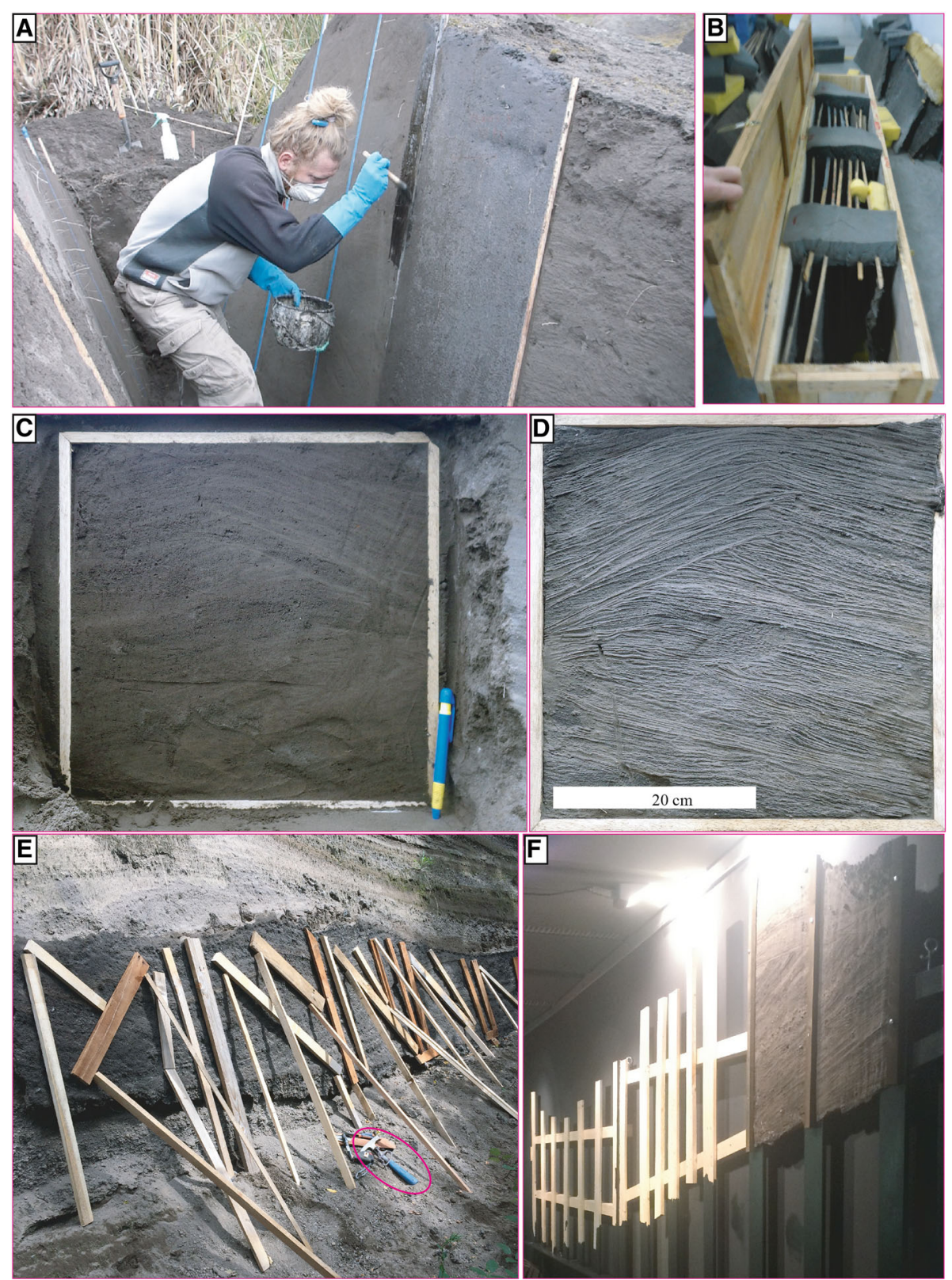

Fig. 1 a Impregnation of a bedform by simple brushing, Tungurahua 2006 deposits. Note delimitation of individual plates with wooden strips separated by sticky tape, flatness of the surface and slight angle to the vertical. b Sediment plates packed in boxes for shipping. c A natural outcrop and $\mathbf{d}$ the resulting sediment plate with enhanced detail level, Tungurahua 2006 pyroclastic currents, note that the exposed (inner side) of the plate is mirroring the outcrop view when taken out. For interpretation, see Douillet et al. (2015). e Lapilli-type sediment plate stabilized with mounting foam and wooden boards at Laacher See before cutting and extracting the plates from outcrop. $\mathbf{f}$ Wooden frames on which sediment plates were mounted during the exhibition "G'Schichten von Tungurahua"

producing sediment plates consists of impregnating the surface of an outcrop with an initially low-viscosity, hardening glue. The viscosity and surface tension of the glue acting with the capillary force and intergranular porosity defines the penetration depth. The difference in uptake, as a function of the grain size distribution, for each lamina enhances sedimentary structures in the resulting plate. In this way, the resulting sample accentuates stratification to a level of detail not otherwise apparent (Fig. 1c vs. 1d). The plates can be stably transported and, therefore, examined in the laboratory without any disruption of the particles or degradation of the structures and textures. In this manner a full preservation of the record of deposition history is retained, and the plates possess the character of consolidated deposits (Fig. 1b). 
Here, a series of tests have been performed on three stratified pyroclastic outcrops of differing grain size distribution and chemical composition (Laacher See/Eifel - Germany, Astroni/Campi Flegrei - Italy, Tungurahua - Ecuador). The technique has also been employed to generate an unprecedentedly large dataset on sediments from pyroclastic currents triggered by the 2006 eruption of Tungurahua (Douillet et al. 2018 a, Douillet et al. 2018 b). Here, we report on the methods tested to produce these sediment plates, the dataset they represent and a range of examples of their uses.

\section{Use}

Sediment plates and lacquer peels have long been employed in the fields of coastal sedimentology, archaeology, and paleontology, and many examples have been used to decorate the walls of universities or museums. The technique was developed in Germany in the 1930s (Voigt, 1933, 1936). The method next received attention from soil scientists and botanists (Tüxen, 1957, Obermöller, 2007) and later from sedimentologists, (in particular from the Utrecht university group (Bouma, 1969, Nio et al. 1980, Van den Berg et al. 2007, Van den Berg and Nio 2010). Initially nitrocellulose or melted vinyl discs were used whereas later polyester and epoxy resins (e.g. Maarse and Terwind 1964, Bouma 1969) were adopted. Impregnation methods have also been used 1) in laboratory studies to consolidate results from flume and other experiments involving clastic sediments (Owen, 1996, Alexander et al. 2001, Baas et al. 2004 ), and 2) to calibrate ground penetrating radar profiles (Van Dam and Schlager, 2000).

Pyroclastic sediments respond very well to the impregnation method and sediment plates or lacquer peels are exhibited in volcano museums around the world (e.g. Sakurajima volcano Visitor Center - Japan, Mount Merapi Museum Sleman - Indonesia, Smithsonian Institution -USA). De Rosa et al. (1992) reported the use of resin in the field with further impregnation in the lab in order to carry out grain analyses at the lamina scale on the stratified ash deposits of La Fossa di Vulcano (Aeolian Vulcano Island, Italy). They were able to extract a $70 \mathrm{~cm}$ thick column representing the entire eruptive sequence. Disk-shaped (ca 10*10*0.5 cm) hardened samples have also been generated from unconsolidated laminated pyroclastic deposits from Capelinhos volcano (Faial Island, Azores, Portugal) employing techniques involving the injection of epoxy with a syringe and the sawing of blocks for thin sections (Klapper et al. 2010).

Sediment plates possess the following advantages as an imaging method:

- Pristine, in-situ preservation of the relative position of individual particles with respect to their neighboring clasts, thereby preserving the organization of small-scale structures such as individual laminae and grain fabrics, and enabling analyses at the lamina scale (Figs. 2-8).

- Enhancement of the visual contrast of details compared to the natural outcrop, as the differences in resin impregnation uptake reinforce the natural contrasts in grain size (Fig. 1c vs. 1d, Fig. 3).

- Consolidation of the initially loose stratified sediments lends them the character of hard rocks, which can be readily sampled for thin section analysis (Fig. 4) or imaging via computer tomography (Figs. 5-6).

- Dissemination is optimized. We have experienced that the educational value of exhibiting plates of real sediments has a high aesthetic appeal and is thus a very useful complement to photographic records. Sediment plates achieve thereby great impact in museums, as artwork, and as educational and public outreach tools in general.

- Conservation enabled through sediment plates is an important opportunity for future researchers, who will herewith have access to an undisturbed dataset long after erosion of the natural outcrop for future techniques of investigation.

\section{Context of the deposits Tungurahua}

Here, the impregnation method has been most extensively applied to the unconsolidated deposits of the 2006 explosive eruption of Tungurahua. This eruption produced pyroclastic currents with two end-member facies associations. 1) Within valleys from the drainage network, coarse grained and massive layers (1-10 m thick and containing clast sizes up to $\mathrm{m}$ scale) were deposited from dense pyroclastic flows behaving as concentrated granular flows (e.g. Kelfoun et al. 2009, Douillet et al. 2013a, Hall et al. 2013, Bernard et al. 2016). 2) A marginal facies association was found on valley overbanks, where ash-dominated, crosslaminated bedsets forming dune bedforms were emplaced in wedge-shape units up to $6 \mathrm{~m}$ in thickness (Douillet et al. 2013a, b). The latter have been interpreted as resulting from diluted currents behaving as highly loaded, turbulent, particulate density currents in a manner similar to turbidity currents. The Tungurahua deposits represent a unique chance to date to investigate in detail well-preserved pyroclastic bedforms with surface exposures in 3D. Adding greatly to the research context of these deposits is the fact that a thorough documentation of outcrops through a survey combining ground penetrating radar (GPR, Dujardin 2014), terrestrial laser scanner (TLS), and the impregnation method has also been accomplished (Douillet et al. 2018a, 2018b). 

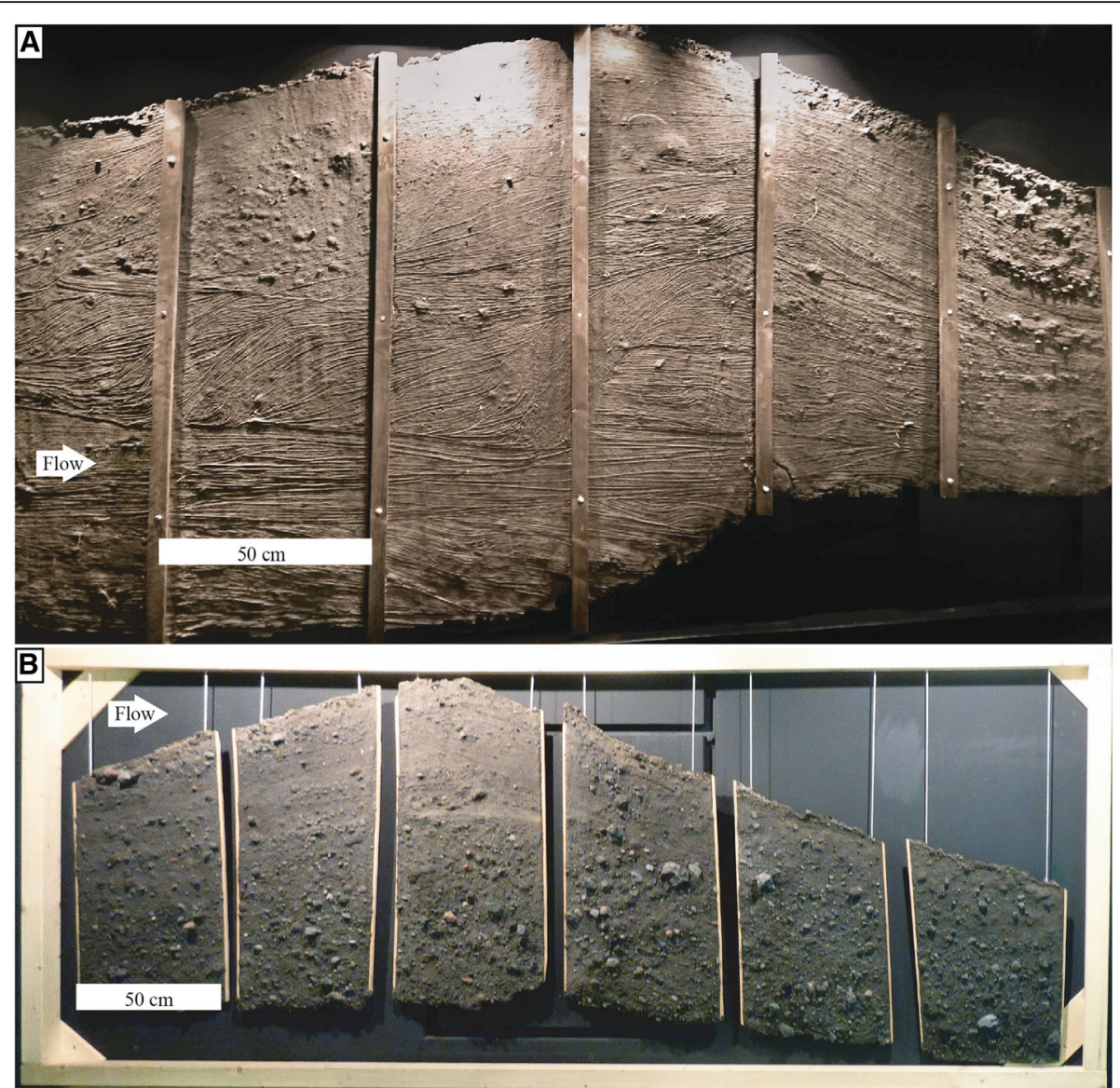

Fig. 2 Sets of six adjacent plates from Tungurahua during the exhibition "G'Schichten von Tungurahua". a Ash-type bedform - the natural outcrop is visible in Fig. 1. b Lapilli-type outcrop

\section{Laacher see}

The Laacher See eruption occurred around $12.9 \mathrm{ka}$ BP. Based on deposit characteristics, the explosivity of the eruption is postulated to have resulted from significant contact of magma with ground water at depth (Van den Bogaard and Schmincke 1984). The deposits contain a significant portion (up to 40\%) of bedrock (Devonian schist), together with fine volcanic ash, and pumiceous lapilli. While deposits of pyroclastic currents have been found several kilometers distant from the inferred vent within valleys around the volcano, fallout deposits have been identified throughout large parts of Central Europe. Dune bedform cross-stratifications are common within the deposits, and consist of particles ranging from coarse lapilli to fine ash, with a typical stoss-depositional nature (Schmincke et al. 1973). Numerous ballistic sags are also present (Douillet et al. 2015).

\section{Astroni}

The Astroni deposits are linked to an explosive eruption of phreatomagmatic origin within the Campi Flegrei caldera at ca. $3.8 \mathrm{ka}$ BP. (e.g Isaia et al. 2004). The presence of several cross-laminated bedsets, intercalated with fall events, indicates several "surge" pulses separated by short periods of quiescence (e.g. Dellino et al. 2004). The sediment plates from Astroni were impregnated in these cross-laminated bedsets (unit U7), where several horizons with $\mathrm{cm}$-sized accretionary pellets were identified.

\section{Sampling methods}

Our methodological experience was gathered primarily by impregnating the deposits of Tungurahua. Other tests were performed on the fine grained cross-stratified ash tuffs from Astroni (Fig. 6), on the coarser grained, pumiceous, cross-stratified, ash-lapilli tuffs from Laacher See (Fig. 8), as well as on ancient fine-ash fallout successions from Tungurahua (Fig. 8c).

Several types of resins have been tested, as well as several methods of impregnation. The textural properties of clasts (pumiceous vs. scoriaceous vs. dense) had no noticeable influence on the impregnated results. The major variable during impregnation and thereby in the character of the final results is clast size. Hereafter, we thus refer to "ash-type" for outcrops dominated by ash (e.g. Tungurahua 

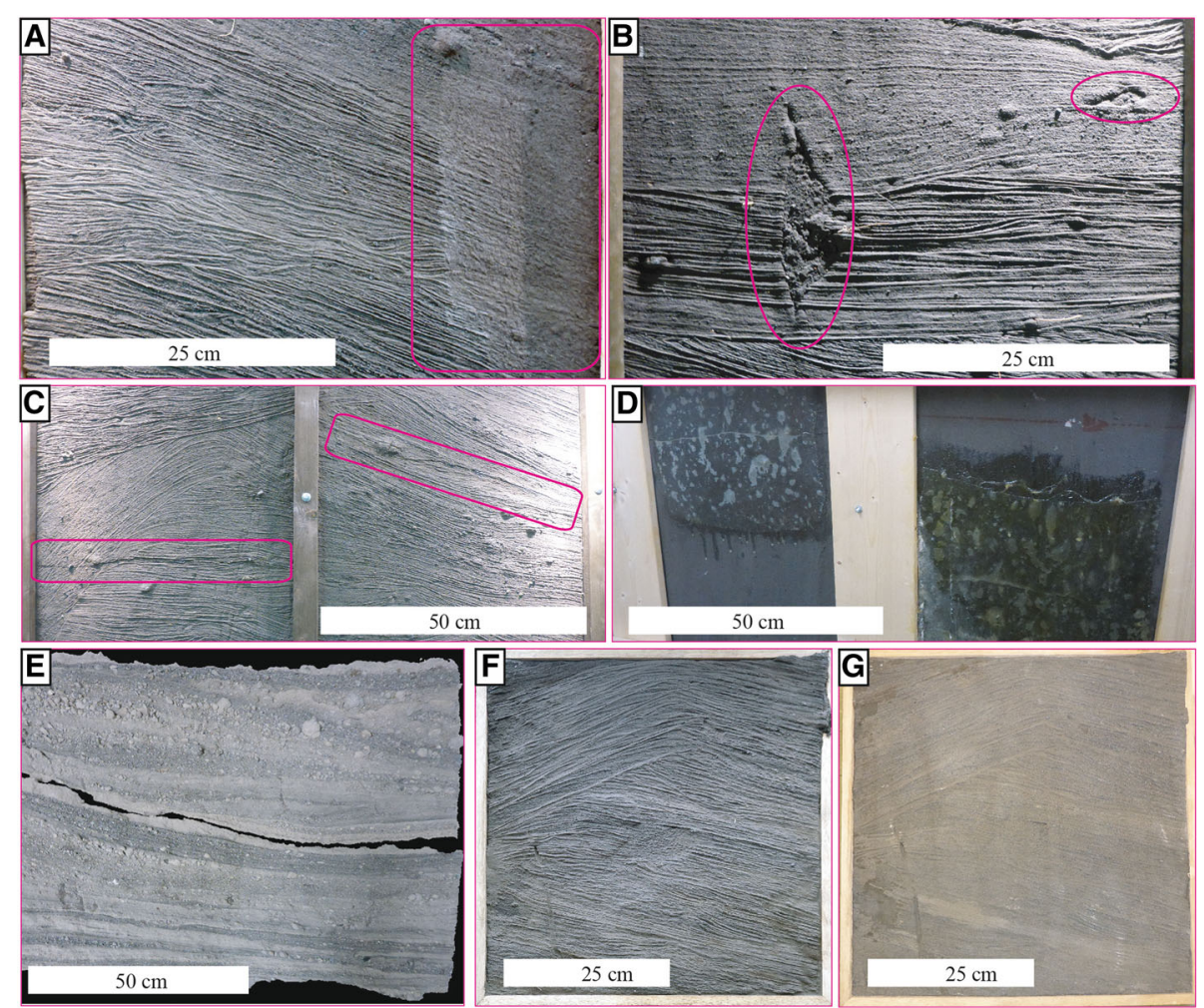

Fig. 3 Undesired results in sediment plates: a Blurry texture, b Peeled off hole without stratification information, c Breakage of sediment plates along stratification $\mathbf{d}$ the back of the same plates repaired with fiber glass. e Sediment plate from Laacher See broken along draping ash layer. $\mathbf{f}$ and $\mathbf{g}$ Effect of illumination: Sediment plate from Tungurahua with adequate skirting light enhancing the stratification. $\mathbf{g}$ Inadequate frontal lighting without shadow effect

or Astroni) and "lapilli-type" for those containing a significant fraction of lapilli and small blocks $(1-10 \mathrm{~cm}$ diam.) in an ash matrix (e.g. Tungurahua or Laacher See), respectively (Fig. 2a vs $2 \mathrm{~b}$ ). A simple outcrop impregnation can be carried out in 2 days of field work. The largest dataset from Tungurahua represents in total the results of 6 weeks of work for the digging and impregnation of the deposits, and collection of the plates (excluding packaging and shipping).

\section{Hardening glue}

Resin

We chose to use a 2-component epoxy (Refs: RE6410 and DE6410) from M.A.CK (https://www.mack-kayak.com//), an epoxy which has been developed for tropical and humid conditions (Table 1). This decision was based on 1) price (less than $15 € / \mathrm{kg}$ in 2012), 2) appropriate viscosity for the accentuation of grain-size variations and thereby enhancement of the stratification, 3) storage longevity (two-component epoxy can be stored for several years without any loss in quality or drying), and 4) practical logistics (M.A.CK was the only company approached that offered shipping to Ecuador).

The one-component epoxy "210 Flits coat colourless" from the "Royal Eijkelkamp Earth Sampling Group B.V" was tested and found to be of similar quality as the M.A.CK. product. However, it was discarded because it

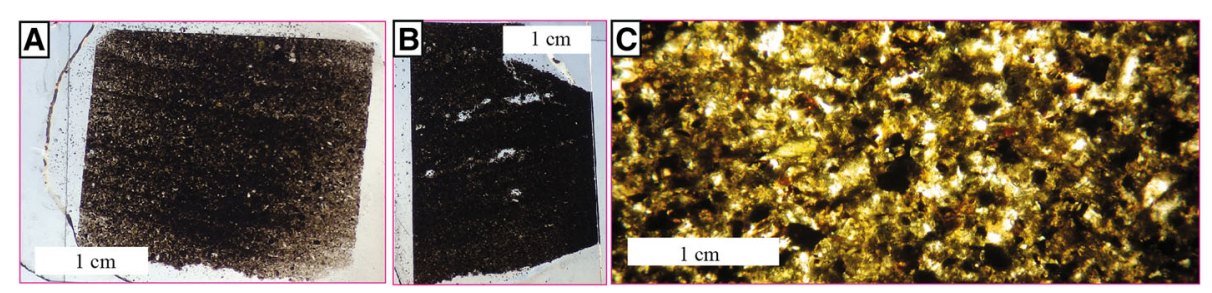

Fig. 4 Thin sections out of sediment plates. a Thin section $(15 \mu \mathrm{m})$ and $\mathbf{b}$ thick section $(25 \mu \mathrm{m})$ with visible lamination. c Ten-fold magnification under the microscope 

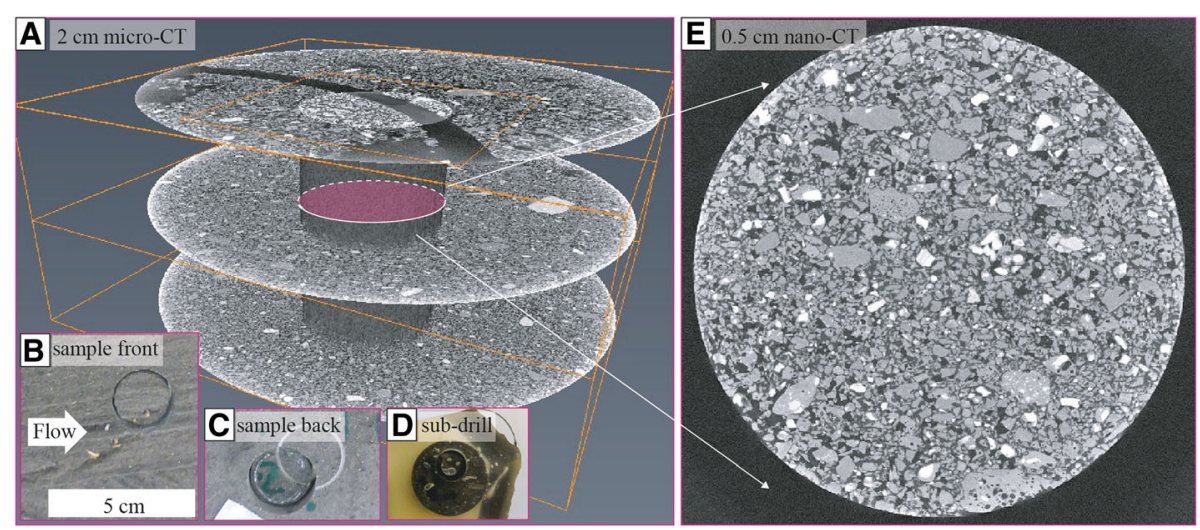

Fig. 5 Micro-computed tomography of Tungurahua samples in plate Transverse-T4-P1. a 3D view of a sample and subsample. b direct view of the $2 \mathrm{~cm}$ diameter sample with visible lamination and $\mathbf{c}$ back-face marked with a stripped line. $\mathbf{d} 0.5 \mathrm{~cm}$ diameter sub-sample drilled in the larger one, with e results at higher resolution on this sub-sample

was more expensive, and after 18 months of storing, the resin had an increased viscosity and lower working time window. An attempt with molding silicone glue was unsuccessful since the silicone was too viscous to penetrate into the sediment and highlight laminations. Epotek-501 has been tested for very small sampling by impregnation of deposits with a syringe, but the price prohibited its use for larger sediment plates. A 3-component polyester mix (resin, hardener, catalyzer) was tested unsuccessfully (at Tungurahua) where the high natural soil humidity impeded the necessary polymerization and hardening.

\section{Thinner}

Acetone is widely accepted as the best diluent. It is inexpensive, mixes well with the resin, and reduces the viscosity of the mixture without noticeably altering the final hardened characteristics. However, acetone could not be purchased legally in Ecuador in the required quantities (it is a major component in the production of cocaine). Therefore conventional gasoline was used as a thinning agent (10 to $20 \%$ in volume). Although it produces an emulsion with the resin, it efficiently lowers the viscosity of the mixture and the final results are only slightly more opaque (i.e., more white in appearance) than is the case with acetone (possibly due to microbubbles of gasoline sealed in the resin). In extreme cases, a soft rubbery texture can result (Fig. 3a). This is attributed to gasoline that remained trapped after the epoxy hardens, where the evaporation of gasoline from the casting mass is incomplete.

\section{Epoxy-hardener mixing}

A ratio of epoxy resin and hardener of $5: 1$ by weight was prepared and stored in separated glass bottles prior to field days (plastic bottles react with these components and dissolve). The resin is tolerant to mixing-ratio errors of $\pm 5 \%$ without significantly changing the hardening efficiency. An over-dose of hardener can trigger a very rapid and exothermal polymerization (within 1 min after mixing). The under-dosing of hardener results in slightly pliable plates. This can be useful when the outcrop is not straight and/or plate-bending is intended for example for exhibition purposes.

A mixture of $1000 \mathrm{~g}$ of resin and $200 \mathrm{~g}$ hardener diluted with approximately $0.2 \mathrm{l}$ gasoline was necessary for the successful fabrication of a $0.5 * 1.5 \mathrm{~m}^{2}$ plate of ash-type outcrops. The resulting plates were typically ca. $0.5 \mathrm{~cm}$ thick and $5-8 \mathrm{~kg}$ in weight (e.g. Fig 2a). For lapilli-type outcrops however, this amount of mixture
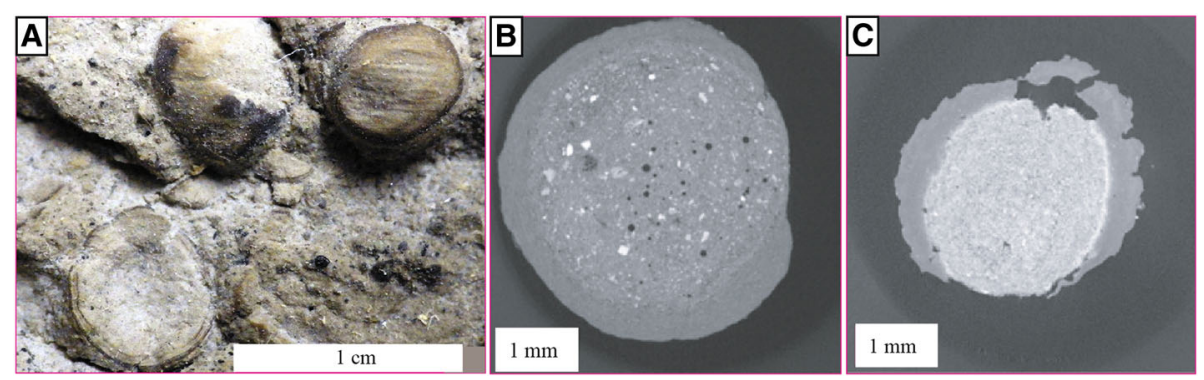

Fig. 6 Accretionary pellets from the Astroni U7 "surge" deposits. b and c Two views from reconstructed micro-computed tomographs 
Table 1 Data on the Epoxy Resin

Company: M.A.C.K. SARL France
Name: résine 6410
Viscosity of the resin: $400 \mathrm{mPa} . \mathrm{s}$
Density of the resin: 1.1
Viscosity of the hardener: $300 \mathrm{mPa} . \mathrm{s}$
Density of the hardener: 0.99
Viscosity of the pure mixture: $350 \mathrm{mPA} . \mathrm{s}($ without acetone or gasoline)
Minimum polymerisation temperature: $10^{\circ} \mathrm{C}$
Temperature of vitreous transition for a polymerisation at room
temperature: $50^{\circ} \mathrm{C}\left(68^{\circ} \mathrm{C}\right.$ for a polymerisation at $60^{\circ} \mathrm{C}$ )

sufficed only for impregnating half of that surface area, resulting instead in thicker and heavier plates (ca. $15 \mathrm{~kg}$ for a $0.5^{*} 0.7 \mathrm{~m}^{2}$ plate, e.g. Fig $2 \mathrm{~b}$ ).

\section{Outcrop preparation \\ Flattening}

The surface to be impregnated was freshly exposed and excavated to be as planar as possible with a vertical inclination of $70-80^{\circ}$ (Fig. 1a). For ash-type outcrops, a T-shaped metal tool was used to plane the surface, whereas for lapilli-type outcrops, making a planar surface is complicated by the presence of large clasts and thus can only be generated roughly using a trowel. This step is fundamental as it determines the final shape of the plate. During the entire preparation phase, the outcrop was sprayed with water in order to avoid crumbling or mechanical erosion during impregnation.

\section{Frames}

For ash-type outcrops, frames prepared directly on the outcrop before impregnation ensured a more aesthetic final plate and greatly reinforced the sediment plates. For small outcrops $(<50 * 50 \mathrm{~cm})$, wooden frames $(0.5$ * $0.5 \mathrm{~cm}$ in cross-section) were fabricated and inserted in the prepared surfaces before application of the epoxy (Fig. 1c-d). In cases where broad dune bedforms were impregnated in several parallel boards, two adjacent long strips (at the height of the impregnated surface) were inserted at a horizontal separation of $50 \mathrm{~cm}$ in order to create easily transportable plates (Fig. 1a-b). The frames or strips were inserted in the outcrop by carefully notching thin, straight grooves, slightly larger than the wooden sticks by scratching with a trowel. After the insertion of the sticks/frames, they were stabilized in the outcrop by plastering the gaps with the previously scratched ash. It is vital to cover with sticky tape the surface of adjacent strips in order to prevent their gluing to each other, otherwise these cannot be separated when epoxy enters along the surface (Fig. 1a).
Thin metal frames $(0.3 * 2 \mathrm{~cm}$ section) were tested and abandoned because: 1 ) insertion in the outcrop was complicated, 2) their re-use for several plates was hindered by a difficult separation of the plates from the frames, 3) such frames were much heavier than wooden sticks and 4) resulting sediment plates tended to break easier at stratification lineations.

For lapilli-type outcrops, (e.g. Laacher See), frames or wooden strips as separation items cannot be inserted. In such cases, the entire section is impregnated as a single plate. After drying, a wooden frame is glued with mounting foam on the surface of the plates before detaching them from the outcrop (Fig. 1e). Individual plates are then cut with a battery-driven angle grinder on the outcrop before plying them off of the outcrop.

\section{Application \\ Brushing}

Many methods and steps are described by Bouma (1969). The simplest method for application of the resin was by simple brushing (Fig. 1a). Keeping the outcrop damp to avoid scratching with the brush, and using a well-soaked brush (4-6 cm breadth), the outcrop was painted from top to base. Brushing should be made by skinning (gliding) tangentially and upward over the surface, and avoiding any brush movement perpendicular to the surface, which can cause peeling off and loss of the sedimentary information in the result (Fig. 3b). Leaking of resin along the surface may produce unaesthetic gullies, and should be kept to a minimum. The outcrops were impregnated with two successive layers, the second layer, being easier to brush and necessitating less resin, is applied ca. 10 min after the first. Lapilli-type outcrops are significantly more complicated to impregnate and leaking and peeling were not entirely avoidable.

\section{Further technical aspects}

Epoxy application by spraying with a nebulizer was tested and found to produce similar results; however, this technique was abandoned because of the higher exposure to inhalable fumes, greater amount of waste (spraying bottles), and its time consuming nature. For lapilli-type outcrops, spraying may be advantageous, since it involves less leaking, but it will remain highly time consuming.

Pinning a cheesecloth or fiber glass on the outcrop before impregnation was tested and found to produce extremely thin peels. The visual aspect was deteriorated compared to direct brushing in our tests and this technique was abandoned. Impregnating a cheesecloth or fiber glass on the outcrop directly after brushing produced peeling off. Applying a strengthening cloth after drying of the outcrop was complicated, added to the weight as well as consumption of resin and was generally unnecessary. 


\section{Post treatment}

\section{Drying and shipping}

After few days hardening (curing) in place, the sediment plates were marked with a code on their outer side. They were then carefully detached from the outcrop by scratching the surrounding unconsolidated ash. Plates were cleaned from adhering unconsolidated material and their outcrop sides (inner side) were left in a direct sunshine in the field for several days in order to evaporate the remaining gasoline and provide the final hardening. It is important to store the plates, weighted down, on a flat surface, in order to avoid undesired warping during the final hardening phase. Cracking at this stage was observed only once along a fine-ash lamina and might be due to the vitreous transition of the resin (which onsets at $50{ }^{\circ} \mathrm{C}$ ), but was not further investigated.

For transport, the sediment plates were packed in large wooden boxes, with each plate separated from its neighbors by spacers and stabilized with Polyurethane foam (Fig. 1b). Having standardized plate sizes is highly convenient for packaging.

\section{Preparation for exhibition}

It is the backside of the surface onto which the resin was applied (the inner side) that exhibits the full plethora of sedimentary details, a result of the variations in resin suction between successive laminae. Sediment plates were washed with a strong water jet in order to remove any loose clasts and dust. Strong supporting wooden structures were created using a horizontal support of two beams $(9 * 7 \mathrm{~cm}$ section) and vertical flat boards $(2 * 14 \mathrm{~cm})$ following the contours of adjacent boards. The sediment plates were clamped against these frames with small planks screwed on the exposed face (Fig. 1f).

Plates were forced flat for exhibition. For this, they were simply progressively clamped on the wooden structures. Over several days, the clamping was progressively increased with screws and nuts. Flattening the plates by clamping too rapidly or non-progressively can break the plates.

The lapilli-type plates are too heavy and too thick to be bendable by clamping with frames. On the other hand however, these plates were robust enough to be hung without frames. Thin cords were simply glued on the back of the plates with Araldite-type epoxy, allowing the plates to be attached with any cable (Fig. 2b).

Adequate lightning is fundamental for exhibition. Since no significant variations in color generally occurs between laminae, the contrast is achieved by illuminating the plates with tangential light $\left(<20^{\circ}\right.$ to the surface), in order to highlight the individual strata with a light-and-shadow effect (compare Fig. 3f and g).

\section{Repair work}

For broken plates, fiberglass cloth combined with the same resin as for impregnation was used (Fig. 3c-d). Without reaching a non-broken strength, two layers of fiberglass render the plate useable for exhibition. "Mat" fiberglass tissues (i.e. randomly arranged, flattened into a sheet) cannot be used, since the glue used for their preparation is incompatible with epoxy, and thus only woven cloth is adequate. A thin cloth with low grammage snugly adapts to the irregularities and roughness of the plates. The outer side of the plate is reinforced, and attention must be paid to avoid resin leaks on the inner side through the cracks, otherwise these droplets will remain on the exposed side.

\section{Weather}

Weather conditions tested have some effect on the method. Impregnation was performed in February in Naples in Italy $\left(5-10{ }^{\circ} \mathrm{C}\right.$, dry), February to April in Ecuador $\left(10-30{ }^{\circ} \mathrm{C}\right.$, very rainy to very sunny), and August in Germany $\left(15-20^{\circ} \mathrm{C}\right.$, cloudy, partially rainy).

Direct sunlight greatly decreases the working time window for application. Additionally, the outcrops tend to lose their humidity-driven cohesion and start crumbling so that water had to be sprayed continuously during preparation and impregnation. No effects on the resulting plates were noted. Whereas light rain and elevated soil humidity were not a problem, stronger rain with large drops falling onto the brush would mix with the resin which rapidly turns to a white color and penetrates less deeply into the outcrop. The resulting plates were found to have insufficiently preserved the stratification information. In summary, the best results have been achieved during cloudy days, at temperatures around $20{ }^{\circ} \mathrm{C}$, no rain, and for high ground-humidity that stabilizes the outcrop.

\section{Use as hard rocks}

\section{Thin sections from Tungurahua PDC plates}

Thin sections were prepared from stratified sections from Tungurahua (Fig. 4). The sediment plate can be handled as one would a consolidated rock, so that both thin (Fig. 4a) and thick (Fig. 4b) sections could be prepared and analyzed microscopically (Fig. 4c). Whereas stratification remains fairly visible macroscopically, it was not recognized in the grain fabrics encountered under the microscope in these preliminary investigations.

\section{Computed tomography}

Samples were drilled from the sediment plates from Tungurahua in order to investigate grain size variations at the lamina scale with computed tomography (Fig. 5). Two subsets were created, the larger ones for $2 \mathrm{~cm}$ diameter samples (Fig. 5a-c) and a second set was 
subsequently re-drilled within the large ones at $0.5 \mathrm{~cm}$ diameter (Fig. 5d-e). Computed tomography measurements using a GE phoenix nanotom $m$ scanner system provided a resolution of $6 \mu \mathrm{m}$ and $2.4 \mu \mathrm{m}$ pixel size for the 2 and $0.5 \mathrm{~cm}$ diameter samples, respectively. For smaller samples individual clasts are well recognized and 2D grain size distribution was computed automatically using several workflows using the software Avizo. Preliminary comparison with manual segmentation shows that $2 \mathrm{D}$ automatic segmentation is reliable and is consequently applicable to compute $3 \mathrm{D}$ grain size distribution.

Further, selected accretionary pellets from the Astroni samples were investigated at $10 \mu \mathrm{m}$-resolution with a GE phoenix v/tome/x s scanner system (Fig. 6). They are massive and poorly-sorted in their central cores, with some exhibiting voids, the sizes of which are comparable to the coarsest particles in the pellets. The central massive cores have oblate shapes, and are coated with a "layer" of darker color that adapts the form to a highly spherical shape by preferential filling of the "troughs". The outer layer is finer grained and seems poorly laminated, with concentric aggradation at the outer surface.

\section{Data}

\section{Sediment plates from the Tungurahua 2006 pyroclastic} currents

Over $50 \mathrm{~m}^{2}$ of sediment outcrops were impregnated in order to preserve each of the four types of dune bedforms previously recognized (Douillet et al. 2013b, 2018a). For each outcrop, a set consisting of 6 neighboring plates was produced aligned with the inferred flow direction (Fig. 2). Each plate is $50 \mathrm{~cm}$ wide and from 1 to $2.2 \mathrm{~m}$ high. Thus, when assembling the plates, they form sets, each of which reflects a $3 \mathrm{~m}$ wide outcrop, which can in some cases cover the entire thickness of a Tungurahua 2006 deposit. For some bedforms, several sets parallel to each other as well as perpendicular cuts between transects were impregnated, in order to document lateral variations within a single bedform (Douillet et al. 2018a). One $6 \mathrm{~m}$ long set was created from the stoss side of one dune bedform to the crest of the next one, in order to document the relationship between successive structures.

The sediment plates reveal fine-scale stratification that is otherwise invisible (Fig. 7). Next to the usual stossaggrading nature of pyroclastic dune bedforms, several observed features were wholly unexpected based on previous

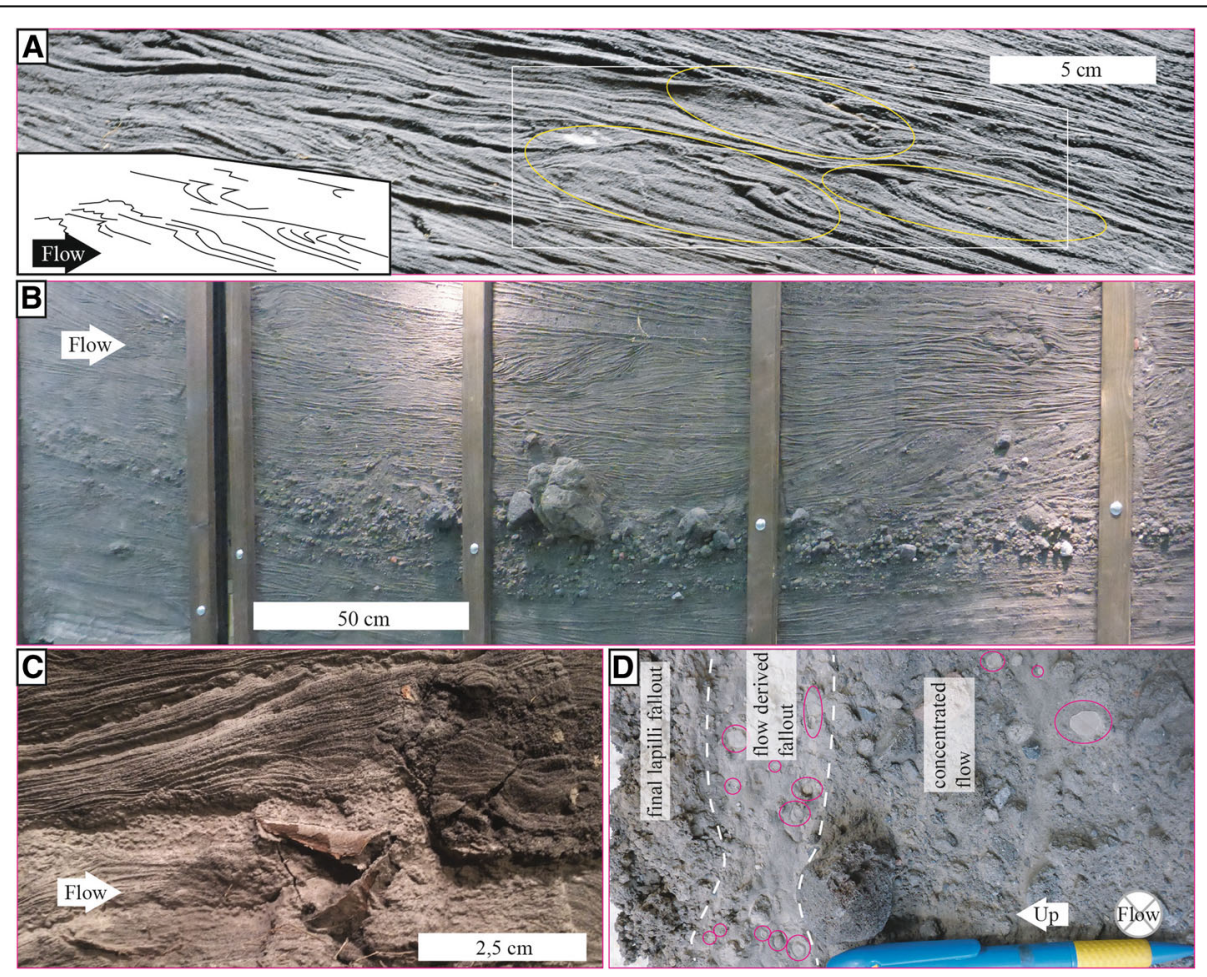

Fig. 7 Variety of sediment structures encountered in the Tungurahua dataset: a "Shark fin" patterns related to syn-depositional soft-sedimentdeformation due to the shear of the flows (see Douillet et al. 2018b). b Isolated block-rich horizon in otherwise synchronous ash dominated beds overlain and underlain by laminated ash beds. c) Intact orchid leaves from an Epidendrum Jamiesonis at the base of the 2006 deposits. The fine grained, light-grey layer might be related to the July 2006 eruption or the initiation of the August 2006 explosions. d Accretionary pellets possibly linked with the encounter of pyroclastic currents with the Chambo river (see Kueppers et al. 2016) 
field investigations (Douillet et al. 2013b). In particular, centimeter scale shear features forming "shark fins" (Douillet et al. 2015, 2018b), overturned lamination underlining erosion planes (Douillet et al. 2017), or "backset ripples" (Douillet et al. 2018a) which have been recognized for the first time here in pyroclastic deposits. Even outcrops that appeared completely massive in the field actually exhibit faint lineations highlighted through grain fabrics and subtle stratification that is readily visible in the sediment plates. These observations would remain inaccessible without the fine-scale imaging power of the impregnation method. These sedimentary features yield a range of novel insights for a dynamics interpretation and may help to unravel the crucial transfers between the basal parts of a pyroclastic current and the substrate.

\section{Tungurahua fine grained fallout plate}

One plate was created on relatively fine-ash (silt size), exhibiting well-laminated planar strata from ancient fallout deposits at Tungurahua (Fig. 8c). The plate $\left(0.5 * 0.5 \mathrm{~m}^{2}\right)$ exhibits extremely well the variations in grain size, yet is very resistant and not breakable. Coalescent ripple beds occur in one lamina set, possibly arising from syn- or post-depositional wind effects. Such aeolian cross-bedding is however very distinct from that of primary PDC bedforms: being much smaller, less extreme in steepness, and lacking steep erosion features.

\section{Laacher see plates}

Two structures were impregnated from the blocky and stratified deposits from Laacher See: a stoss-depositional bedform made of faintly defined backset strata (Fig. $8 \mathrm{a}-\mathrm{b})$ and a complex soft sediment deformation structure from a ballistic impact (Fig. 8d, Douillet et al. 2015). Both are around $5 \mathrm{~m}$ in length and between 0.5 and $1.3 \mathrm{~m}$ in height. They were impregnated as a single plate before being stabilized with mounting foam and wooden boards and subsequently cut in place with an angle-grinder (Fig. 1e). As for ash-type bedforms from Tungurahua, the sediment plates exhibit an enhanced stratification, even for layers seemingly massive before impregnation. They are also heavier and thicker due to their coarser grained nature, and more breakable, this being a consequence of the presence of much finer (ash) draping layers within the structures.

\section{Accretionary pellets from Astroni and Tungurahua}

The sediment plates from Astroni demonstrate the efficacy of the method on relatively fine ash sediments. Numerous accretionary pellets (Brown et al. 2012) were preserved in some massive, fine ash layers, and here

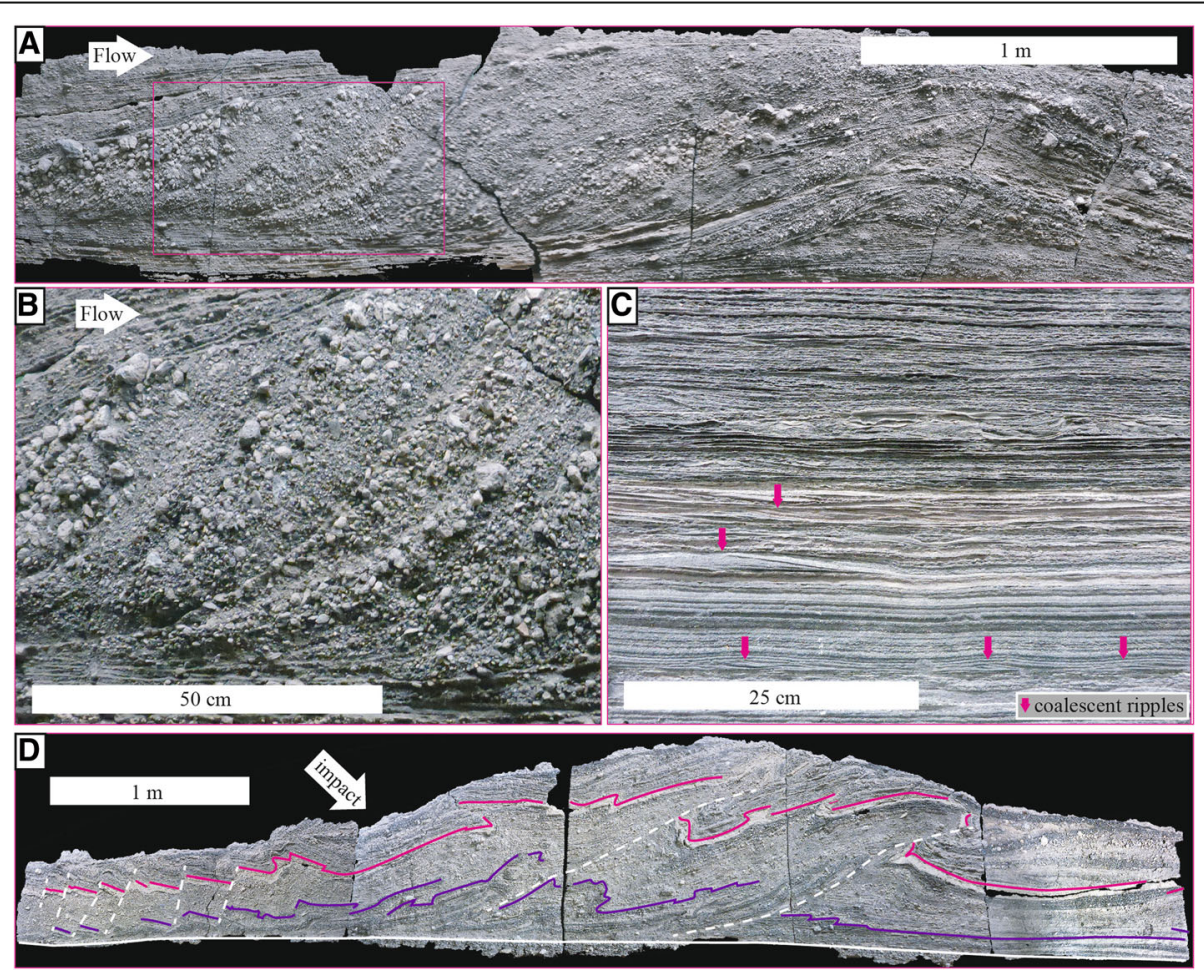

Fig. 8 a A stoss-depositional bedform from Laacher See with pink box indicating the zoomed zone on the stratal fabrics in $\mathbf{b}$. $\mathbf{c}$ Fine grained fallout deposits from ancient eruptions at Tungurahua, with slight wind reworking evidences (arrows point at ripple beds). $\mathbf{d}$ Unconventional impact sag at Laacher See (see Douillet et al. 2015 for interpretation) 
again, the impregnation method was highly effective in conserving the fine details of internal organization with full pellets extracted (Fig. 6). The latter have a diameter of ca. $0.5 \mathrm{~cm}$ and consist of an outer concentric rim of fine volcanic ash around a structureless core.

Accretionary pellets were also observed at a single locality of the 2006 Tungurahua deposits. The top $15 \mathrm{~cm}$ of deposits of otherwise coarse grained, massive, meter thick layers emplaced by "concentrated" pyroclastic flows contain rounded, undisturbed, accretionary pellets up to $8 \mathrm{~mm}$ in diameter. They consist of fine ash. Several ppm of soluble sulphate and chloride salts were detected from aqueous leaching measurements after $1 \mathrm{~h}$ in deionized water. These accretionary pellets were identified in a single confined area of the 2006 deposits. The location of the pellet is related to a zone where dense pyroclastic flows entered and dammed the Chambo river for several hours. It has been proposed that the steam resulting from pyroclastic currents entering the river would provide a sufficient level of humidity to trigger the formation of these accretionary structures (Kueppers et al. 2016).

\section{Exhibition and further usage}

Part of the sediment plate dataset from Tungurahua was used for a special exhibition in summer 2016 at the Mineralogy Museum in Munich (G'Schichten vom Tungurahua, Douillet et al. 2016). Over 1500 visitors were registered during the 30-day exhibition. The plates mainly served as a dissemination tool for an introduction to sedimentology and were used to illustrate several concepts including:

-The granular nature of deposits from explosive volcanic eruptions,

-The difference between massive and stratified deposits,

-The links between time and stratal aggradation,

-The phases of a flow, -sedimentation, erosion, hiatus-, and.

-The three "Steno" principles of stratigraphy: lateral continuity, superposition, deposition following existing surface (demonstrated by "the great Islamic scholar Avicenna or Îbn-Sînâ", 980 to 1037, see Fisher and Garrison 2009).

Regarding teaching, the dataset was presented during lectures, as an actual example of real volcanic deposits. Although geology and sedimentology concepts had been taught theoretically during classes, it became clear that when discussing these principles in front of the sediment plates, applying this knowledge and using it for interpretation was typically not fully grasped. Exercises involving the description, correlation, and interpretation of the dataset can be carried out. Fine-scale features of the plates also initiated student research projects. The dataset has also been used in Munich as contribution to meetings (Physics of Volcanoes 2017) and short courses (Melts, Glasses, Magmas 2016, 2017).

\section{Conclusions}

Unconsolidated outcrops of pyroclastic sediments were impregnated with a low-viscosity, two-component epoxy resin in order to produce sediment plates that can be extracted and transported. In this manner, sedimentary information can be excavated and fully preserved in its pristine state including grain and lamina organization. All types of tested sediments reacted well to the method, from fine-ash lamination to coarse-lapilli massive mixtures, including accretionary pellets and cross-beds. All impregnated outcrops had their structure pronounced to a much higher degree in the resulting plates than initially visible in the outcrop.

The sediment plates can be investigated in the manner of consolidated rocks by means of thin section analysis or computer tomography. In this way, the undisturbed structures can be observed and the evolution of a bedform can be traced on a fine scale ( $\mathrm{mm}$ laminae). The variety, small scale, and detail level of sedimentary features visible is unprecedented and could not be described via the field analysis of unconsolidated deposits. Such field examples contribute to our understanding of the transfer of material, turbulence, and energy between the bed, basal part of pyroclastic currents, and its upper parts. The data provide new challenges to and sometimes support for our models of transport, deposition and erosion of pyroclastic material.

The aesthetic aspect of the set of sediment plates is appealing and represents a powerful tool for scientific and public dissemination. It has been used in various contexts, as a museum exhibition, in short courses and workshops, and for regular course teaching.

\section{Acknowledgements \\ This project is supported by the Deutsche Forschungsgemeinschaft grant D01953/1-1 to GAD. GAD acknowledges financial support by the Bavarian grant "Thesis" as well as BayLat (project CoCotE). GAD and UK were supported by the Deutsche Forschungsgemeinschaft grant KU2689/2-1. QC was supported by the Alsacian grant "Boussole" and the European grant program "Erasmus". I.H. P.W. and R.R. were supported by the LMU student support "Studi_forscht@LMU". GAD and UK thank Sandro di Vito of Istituto Nazionale di Geofisica e Vulcanologia, Sezione di Napoli, for logistical help during fieldwork in the Astroni crater, and members of the Instituto Geofísico for help at Tungurahua. M.A.CK ${ }^{\circledast}$ is acknowledged for their support and shipping the epoxy to Ecuador. H.W. Lohringer is acknowledged for his information on existing datasets in Germany. M Kaliwoda and R. Hochleitner are acknowledged for supporting the exhibition in the Museum Reich der Kristalle in Munich. DBD wishes to acknowledge the support of an ERC Advanced Grant EVOKES (247076).}

Ethical approval and consent to participate Not applicable.

The authors declare that they have no competing interests

\section{Funding}

-DFG-DO1953/1-1 (to GAD): Salary for GAD during analysis and writing, material for mounting and making exhibition, gratifications for QC, fieldwork at Laacher See.

-DFG-DO2689/2-1 (to UK): Salary for GAD and fieldwork to Astroni.

-THESIS (to GAD): salary for GAD (2010-2012) and epoxy costs. 
-Baylat CoCotE (to GAD): Field work in Ecuador for GAD and RR. -Boussole (to QC): Complementary daily allowance for QC. -Erasmus (to QC): Complementary daily allowance for QC. -ERC Evokes (to DBD): Field campaign in 2015 for GAD and UK through DBD. -Studi_forscht@GEO (to RR; IH; PW): 5 LMU internal grants for epoxy costs as well as gratifications for $\mathrm{RR}, \mathrm{IH}, \mathrm{PW}$.

-Arielle Douillet (to GAD): Regular source of food for GAD during the writing phase of the manuscript.

\section{Availability of data and materials}

The dataset of sediment plate is stored in the "Gesteinslager" (Rock repository) of the Mineralogy section of LMU (Theresienstrasse 41 , Munich Germany. It can be freely accessed after taking contact with the main author or responsible of department to get access to the room.

\section{Author's contributions}

GAD organized the logistics and carried the field campaigns, the analysis of deposits, supervised the students involved, and wrote the main part of the manuscript. UK participated in part of all field campaigns and supported the project. CM participated in 14 days of the field campaign in Ecuador. QC participated in the mounting of part of the frames and analysis of deposits with micro-CT. MB participated in the field campaign at Laacher See and mounted the exhibition. RR participated in the field campaign at Laacher See and tests in Ecuador. IH participated in a large part of the post treatment and mounting of the frames. PW participated in a large part of the post treatment and mounting of the frames. $\mathrm{KUH}$ carried part of the $\mathrm{CT}$ measurements. AC carried part of the $C T$ measurements. DBD supported the project, funded the main field campaign in Ecuador, revised and edited the manuscript. BB participated in part of the field campaign in Ecuador. All authors read and approved the final manuscript.

\section{Consent for publication}

One photo (Fig. 1) includes the main author Guilhem Amin Douillet. I hereby approve the use of my image in this manuscript.

\section{Competing interests}

\section{Publisher's Note}

Springer Nature remains neutral with regard to jurisdictional claims in published maps and institutional affiliations

\section{Author details}

${ }^{1}$ Earth and Environmental Sciences, Ludwig-Maximilians-Universität München, München, Germany. ${ }^{2}$ Institut für Geologie, Universität Bern, Bern, Switzerland. ${ }^{3}$ Université Joseph Fourier Grenoble, Grenoble, France. ${ }^{4}$ Ecole Et Observatoire des Sciences de la Terre, Université de Strasbourg, Strasbourg, France.

${ }^{5}$ Zoologische Staatssammlung München, München, Germany. ${ }^{6}$ Instituto Geofisico, Escuela Politécnica Nacional Quito, Quito, Ecuador.

Received: 5 February 2018 Accepted: 25 September 2018

\section{Published online: 08 October 2018}

\section{References}

Alexander J, Bridge JS, Cheel RJ, Leclair SF. Bedforms and associated sedimentary structures formed under supercritical water flows over aggrading sand beds. Sedimentology. 2001;48(1):133-52.

Baas JH, Van Kesteren W, Postma G. Deposits of depletive high-density turbidity currents: a flume analogue of bed geometry, structure and texture. Sedimentology. 2004;51:1053-88.

Bernard J, Eychenne J, Le Pennec JL, Narváez D. Mass budget partitioning during explosive eruptions: insights from the 2006 paroxysm of Tungurahua volcano, Ecuador. Geochem Geophys Geosyst. 2016;17(8):3224-40.

Bouma A.H. (1969) Methods for the Study of Sedimentary Structures. Wiley, New York; N.Y., 458 pp.

Brown RJ, Bonadonna C, Durant AJ. A review of volcanic ash aggregation. Phys Chem Earth. 2012;45-46:65-78

De Rosa, R., Frazzetta, G., La Volpe, L. (1992). An approach for investigating the depositional mechanism of fine-grained surge deposits. The example of the dry surge deposits at "La Fossa di Vulcano". J Volcanol Geotherm Res, 51(4), 305-321.
Dellino P, Isaia R, Veneruso M. Turbulent boundary layer shear flows as an approximation of base surges at Campi Flegrei (southern Italy). J Volcanol Geotherm Res. 2004;133(1):211-28.

Douillet G.A., Bernard B., Bouysson M., Chaffaut Q., Dingwell D.B., Gegg L., Holscher I., Kueppers U., Mato C., Ritz. V., Schlunegger F., Witting P. (2018a) Pyroclastic dune bedforms: macroscale structures and lateral variations. Examples from the 2006 pyroclastic currents at Tungurahua (Ecuador). Sedimentology. https://doi.org/10.1111/sed.12542.

Douillet GA, Bouysson M, Gegg L. Overturned strata in deposits of dilute pyroclastic density currents, field and analogue data. Portland, Oregon: IAVCEl general Assembly 2017; 2017.

Douillet G.A., Chaffaut Q., Schlunegger F., Kueppers U., Dingwell D.B. (2018b) Shark fins: overturned flame patterns due to waves at the shear horizon of a flow-bed boundary. Examples from the 2006 pyroclastic currents deposits at Tungurahua. Manuscript submitted to sedimentology. Preprint available at https://eartharxiv.org/e8apk/.

Douillet GA, Kueppers U, Mato C, Bouysson M, Broschat N. G'Schichten von Tungurahua, Ablagerungen des Vulkanausbruchs vom 17. August 2006. Munich Germany: Museum Reich der Kristalle; 2016. Exhibition from 17.08.2016-20.09.2016

Douillet GA, Pacheco DA, Kueppers U, Letort J, Tsang-Hin-Sun È, Bustillos J, Hall M, Ramón P, Dingwell DB. Dune bedforms produced by dilute pyroclastic density currents from the august 2006 eruption of Tungurahua volcano. Ecuador, Bulletin of Volcanology. 2013b;75:1-20.

Douillet G.A., Taisne B., Tsang-Hin-Sun E., Mueller S.K., Kueppers U., Dingwell D.B. (2015) Syn-eruptive, soft-sediment deformation of dilute pyroclastic density current deposits: triggers from granular shear, dynamic pore pressure, ballistic impacts and shock waves. Solid earth discussion. https://www.solidearth.net/6/553/2015/se-6-553-2015.pdf.

Douillet GA, Tsang-Hin-Sun Ė, Kueppers U, Letort J, Pacheco DA, Goldstein F, Von Aulock F, Lavallée Y, Hanson JB, Bustillos J, et al. Sedimentology and geomorphology of the deposits from the august 2006 pyroclastic density currents at Tungurahua volcano, Ecuador. Bull Volcanol. 2013a;75:1-21.

Dujardin JR. Imagerie géoradar (GPR) en milieu hétérogène: application aux failles actives en Mongolie et aux dépôts pyroclastiques du Tungurahua (Equateur): Doctoral dissertation. Strasbourg; Université de Strasbourg; 2014

Fischer AG, Garrison RE. The role of the Mediterranean region in the development of sedimentary geology: a historical overview. Sedimentology. 2009:56(1):3-41.

Hall ML, Steele AL, Mothes PA, Ruiz MC. Pyroclastic density currents (PDC) of the 16-17 august 2006 eruptions of Tungurahua volcano, Ecuador: geophysical registry and characteristics. J Volcanol Geotherm Res. 2013;265:78-93.

Isaia, R., D’Antonio, M., Dell'Erba, F., Di Vito, M., Orsi, G. (2004). The Astroni volcano: the only example of closely spaced eruptions in the same vent area during the recent history of the Campi Flegrei caldera (Italy). J Volcanol Geotherm Res, 133(1), 171-192.

Kelfoun K, Samaniego P, Palacios P, Barba D. Testing the suitability of frictional behaviour for pyroclastic flow simulation by comparison with a well-constrained eruption at Tungurahua volcano (Ecuador). Bull Volcanol. 2009;71(9):1057.

Klapper D, Kueppers U, Castro JM, Pacheco JMR, Dingwell DB. Impregnating unconsolidated pyroclastic sequences: a tool for detailed facies analysis. Geophys Res Abstr. 2010;12:EGU2010-11780.

Kueppers U., Ayris P.M., Bernard B., Delmelle P., Dobson K., Douillet G.A., Lavallée Y., Mueller S.B., Dingwell D.B. (2016) Volcano vs. Environment: Where, when and why does ash aggregate? Cities on Volcanoes meeting, November 2016.

Maarse $\mathrm{H}$, Terwindt JHJ. A new method of making lacquer peel sections. Mar Geol. 1964;1(1):98-105

Melts, Glasses, Magmas. 17th Edition of the short course. 13-17.06.2016, LudwigMaximilians-Universität München. Munich Germany: Dingwell D.B; 2016.

Melts, Glasses, Magmas. 18th Edition of the short course. 10-15.07.2017, LudwigMaximilians-Universität München. Munich Germany: Dingwell D.B.; 2017.

Nio S.W., van den Berg J.H., Goesten M., Smulders F. (1980) Dynamics and sequential analysis of a mesotidal shoal and intershoal channel complex in the eastern Scheldt (southwestern Netherlands). Sediment Geol, 26 263-279.

Obermöller M. (2007) Begleitschrift zur Sonderausstellung "Boden schreibt Geschichte. Lackprofile-Erdgeschichtliche Abziehbilder." Schriftenreihe des Landesmuseums für Natur und Mensch, Landesmuseum für Natur und Mensch 52. Primus-Verlag, ISBN: 3896789953, 9783896789952. 222pp.

Owen G. Experimental soft-sediment deformation: structures formed by the liquefaction of unconsolidated sands and some ancient examples. Sedimentology. 1996;43(2):279-93. 
Physics of Volcanoes 2017. Third workshop on Physics of Volcanoes, 8-9.03.2017, Ludwig-Maximilians-Universität München, Munich Germany. Hess. K.U. and Kueppers U.

Schmincke HU, Fisher RV, Waters AC. Antidune and chute and pool structures in the base surge deposits of the Laacher see area, Germany. Sedimentology. 1973;20(4):553-74.

Tüxen R. (1957) Die Schrift des Bodens: kurzer Führer durch die Sammlung von Bodenprofilen nordwestdeutscher Wald-und Heidegesellschaften aus der Bundesanstalt für Vegetationskartierung. Bundesanst. für Vegetationskartierung.

Van Dam RL, Schlager W. Identifying causes of ground-penetrating radar reections using time-domain reectometry and sedimentological analyses. Sedimentology. 2000;47:435-49.

Van den Berg J.H., Boersma J.R., Van Gelder A. (2007) Diagnostic sedimentary structures of the fluvial-tidal transition zone - evidence from deposits of the Rhine and Meuse. Netherlands Journal of Geosciences - Geologie en Mijnbouw 86-3 287-306.

Van den Berg J.H., Nio S.W. (2010) Sedimentary structures and their relation to bedforms and flow conditions. EAGE publications, The Netherlands. ISBN 978-90-73781-76-4.

Van den Bogaard P, Schmincke HU. The eruptive center of the late Quaternary Laacher see tephra. Geol Rundsch. 1984;73(3):933-80.

Voigt E. Die Übertragung fossiler Wirbeltierleichen auf Zellulose-Filme, eine Bergungsmethode für Wirbeltiere aus der Braunkohle. Palaeontol Z. 1933;15:72-8.

Voigt E. Ein neues Verfahren zur Konservierung von Bodenprofilen. Z.

Pflanzenerneuerung. Düngung und Bodenkunde. 1936;45:111-5.

Ready to submit your research? Choose BMC and benefit from:

- fast, convenient online submission

- thorough peer review by experienced researchers in your field

- rapid publication on acceptance

- support for research data, including large and complex data types

- gold Open Access which fosters wider collaboration and increased citations

- maximum visibility for your research: over $100 \mathrm{M}$ website views per year

At $\mathrm{BMC}$, research is always in progress.

Learn more biomedcentral.com/submissions 